\section{HUMANASE SOCIAIS}

V.9 N.2 $2021 \cdot$ Fluxo Contínuo

ISSN Digital: 2316-3801

ISSN Impresso: 2316-3348

DOI: 10.17564/2316-3801.2021v9n2p154-165

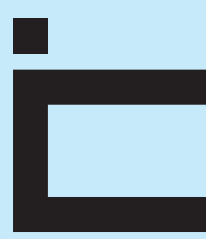

开N

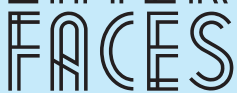

CIENTÍFICAS

\title{
MUDANCGAS E PERMANÊNCIAS: PERCEPÇÕES DE HOMENS/PAIS SOBRE PATERNIDADE E VIDA FAMILIAR
}

CHANGES AND PERMANENCES: PERCEPTIONS OF MEN/ FATHERS ABOUT FATHERHOOD AND FAMILY LIFE

\author{
CAMBIOS Y PERMANECIAS: \\ PERCEPCIONES DE HOMBRES/PADRES SOBRE \\ LA PATERNIDAD Y LA VIDA FAMLLIAR
}

Natália Benegas Vieira ${ }^{1}$

Maria de Fátima de Campos Françozo ${ }^{2}$

Artigo derivado da dissertação de Mestrado, de título "A família na ótica do pai: envolvimento e participação?" Desenvolvida no Programa de Pós-Graduação em Saúde, Interdisciplinaridade e Reabilitação, da Faculdade de Ciências Médicas, da Universidade Estadual de Campinas, orientada pela Prof. Dra. Maria de Fátima de Campos Françozo, concluída em 2017.

\section{RESUMO}

A realidade brasileira viveu transformações políticas, sociais, econômicas e culturais no último século que levaram a modificações na família em termos de sua organização e formas de viver. As definições de gênero foram questionadas e as funções parentais se alteraram, impactando no papel do homem e pai, que foi chamado a ter maior envolvimento na dinâmica familiar. Assim, este estudo teve por objetivo conhecer a percepção de homens que são pais sobre sua participação na vida familiar e no cuidado dos filhos. Tratou-se de uma pesquisa qualitativa, realizada por meio de entrevistas semiestruturadas. Foram participantes da pesquisa 14 pais de lactentes, usuários de um Programa de Triagem Auditiva Neonatal de um Hospital Universitário, do Estado de São Paulo. As entrevistas foram gravadas e os dados categorizados e analisados por Análise de Conteúdo. Os resultados revelaram que para o homem, a transição para o papel de pai indica a passagem para a vida adulta e se constitui, sobretudo, em assumir responsabilidades pelo filho e pela família. Neste sentido, ser o provedor financeiro revelou-se como um ideal. 0 exercício da paternidade centrou-se no envolvimento afetivo em relação aos filhos e no educar. Embora existam iniciativas de ajuda por parte dos pais nas tarefas domésticas e de cuidados, estas são ainda prioritariamente femininas, permanecendo o caráter subsidiário do homem nesta questão.

\section{PALAVRAS-CHAVE}

Relações Familiares. Paternidade. Gênero. Masculinidade. 


\section{ABSTRACT}

The brazilian reality has experienced political, social, economic and cultural transformations in the last century that have led modifications in the family in terms of its organization and ways of living. The definitions of gender were questioned and the parental functions have changed, impacting on the role of man and father, who was called to have greater involvement in family dynamics. Thus, this study aimed to know the perception of men who are parents about their participation in family life and in the care of their children. It was a qualitative research, carried out through semi-structured interviews. Participated in the research 14 parents of infants of a Neonatal Hearing Screening Program of a Public University, in São Paulo State. The interviews were recorded and the data categorized and analyzed through Content Analysis. The results revealed that for men, the transition to fatherhood indicated the transition to adult life meaning mainly, taking responsibilities for the family and children. For them being the financial provider of the family was seen as an ideal. The role of fatherhood means affective involvement and education of the children. Still, the results showed that household and care for the children are seen as primarily female functions, remaining a subsidiary role of man at that point.

\section{KEYWORDS}

Family Relations. Fatherhood. Gender. Masculinity.

\section{RESUMEN}

La realidad brasileña ha sufrido transformaciones políticas, sociales, económicas y culturales en el ultimo siglo que condujo a cambios en la familia en relación con la organización y las formas de vida. Se cuestionaron las definiciones de género y se modificaron las funciones parentales, impactando el papel del hombre y el padre, quienes fueron llamados a involucrarse en la dinámica familiar. Sendo así, Este estudio tuvo como objetivo conocer la percepción de los hombres que son padres sobre su participación en la vida familiar y el cuidado de los niños. Fue una investigación cualitativa, realizada a través de entrevistas semiestructuradas. Los participantes del estudio fueron 14 padres de bebés, usuarios de un Programa de Evaluación Auditiva Neonatal en un Hospital Universitario, en el estado de São Paulo. Las entrevistas fueron grabadas y los datos categorizados y analizados a través del Análisis de Contenido. Los resultados revelaron que para los hombres, la transición al papel de padre indica la transición a la edad adulta y constituye, sobre todo, asumir la responsabilidad del niño y la família. En este sentido, ser el proveedor financiero demostró ser un ideal. La paternidad se centra en la participación afectiva en relación con los niños y la educación. 
aunque los padres ayudan con las tareas domésticas y el cuidado, estos siguen siendo principalmente femininos, quedando el carácter subsidiario del hombre en este punto.

\section{PALABRAS CLAVES}

Relaciones familiares. Paternidad. Género. Masculinidad.

\section{INTRODUCÇÃO}

A família brasileira passou por diversas transformações ao longo do tempo, que culminaram nos modos de ser e organizar-se atualmente.

As investigações de Neder (1994) indicam que as mudanças trazidas pela industrialização e modernização no país, a partir dos anos de 1930, impactaram diretamente nos modos de viver das famílias, mudando não apenas suas rotinas, mas também seu tamanho e os papéis de seus membros.

Até então o papel da mulher era o de mãe e de suporte para o homem, para que este pudesse trabalhar fora de casa. Enquanto ela era responsável pelo que se denomina espaço privado, no cuidado com os filhos e com as tarefas domésticas, os homens pertenciam ao mundo público, por meio, predominantemente, do trabalho (NEDER, 1994).

Essa condição recebeu fortes críticas de movimentos como o feminista, que iniciou uma mobilização em grande escala na década de 1960, exigindo maior participação da mulher na educação, vida política e trabalho (NEDER, 1994).

Outras mudanças econômicas, sociais e culturais ocorreram nas décadas seguintes, que para Sarti (2010), reconfiguraram profundamente os núcleos familiares. Segundo a autora, o avanço das tecnologias de reprodução humana e a popularização da pílula anticoncepcional foram decisivas para oferecer liberdade à mulher e para o surgimento das famílias pequenas, nucleares. A legalização do divórcio também foi importante instrumento gerador de mudanças, como no caso das famílias reconstituídas, e a criação de exames de DNA que possibilitou responsabilizar homens em seu papel de pai, oferecendo proteção à criança e à mulher.

Essa série de mudanças somadas à saída da mulher para o mercado de trabalho, foi capaz de criar novos códigos e articulações no âmbito familiar, repercutindo no papel desempenhado pelo pai, antes representada pela figura de provedor, poder e ordem moral na família (DEL PRIORE, 2013), exigindo deles maior envolvimento e participação, repensando e questionando, dessa forma, os delimitados papéis de gênero.

Ressalta-se aqui que gênero se refere à construção social do masculino e do feminino, a papéis definidos e comportamentos apropriados para o ser homem e o ser mulher em determinada sociedade (GOMES, 2008). Entende-se que cada gênero se cruza com outros elementos, como classe, poder, raça/etnia, geração e orientação sexual, por isso, deve-se falar em feminilidades ou masculinidades (GOMES, 2008).

Em meio à pluralização dos rótulos de masculinidades iniciados no país a partir de 1970, quando tentam suavizar o estereótipo de homem forte e viril para o 'novo homem', a denominação do 'novo pai' 
também começa a ser veiculada, incentivando que os pais não sejam apenas provedores materiais, mas passem a se envolver nos cuidados e educação dos filhos (DEL PRIORE, 2013; FREITAS et el., 2009).

Portanto, ao considerar estes condicionantes históricos, afirma-se que as expectativas em relação ao homem no contexto familiar se transformaram, mas pouco se sabe como atualmente tais mudanças se traduzem na rotina familiar, sobretudo, por meio do olhar dos próprios homens.

Assim, este estudo teve como objetivo compreender a percepção que homens/pais têm sobre sua participação na vida familiar e no cuidado dos filhos, revelando, portanto, importantes perspectivas sobre definições de papéis que ainda permanecem e mudanças que se afiguram no cotidiano familiar.

\section{MÉTODO}

O projeto de pesquisa foi aprovado pelo Comitê de Ética em Pesquisa da Universidade Estadual de Campinas (UNICAMP), em 20/08/2015, sob o número 1.181.568, sendo posteriormente conduzido de acordo com os padrões éticos exigidos.

O estudo foi desenvolvido por meio do método qualitativo (MINAYO, 2009), uma vez que este meIhor se adequou às finalidades da investigação. Foram participantes da pesquisa 14 pais de lactentes que compareceram a um Programa de Triagem Auditiva Neonatal de um Hospital Universitário, do Estado de São Paulo e foi realizada entre os meses de agosto de 2015 a outubro de 2016. Os pais foram escolhidos aleatoriamente, independentemente da idade, escolaridade ou número de filhos. Todos que voluntariamente participaram, assinaram o Termo de Consentimento Livre e Esclarecido (TCLE).

Para a coleta de dados, optou-se por realizar entrevistas semiestruturadas de forma individual, tendo como auxílio um gravador de voz, para após serem transcritas na íntegra. A coleta foi interrompida quando se constatou a saturação de dados, ou seja, quando as respostas apresentaram certa regularidade e redundância (DESLANDES, 2009).

Para a análise dos dados, foi utilizado o modelo de Análise de Conteúdo, conforme proposto por Bardin (2010). Os resultados foram categorizados e a discussão realizada a partir dos núcleos de sentido.

Todos os participantes foram identificados por nomes fictícios, de maneira a manter o sigilo dos dados.

0 perfil dos participantes compreende pais da idade entre 22 a 54 anos. Sete deles eram casados e os outros sete também viviam com a companheira, de modo que todos mantinham um relacionamento com a mãe do filho que foi levado para realizar a Triagem.

A composição familiar variou de três a seis membros e a renda era composta em oito famílias exclusivamente pelo participante, e as demais, por outros membros (esposa/outro familiar). Em relação à situação socioeconômica, a renda média das famílias era de 3,4 salários mínimos. Todos eram usuários do SUS.

\section{RESULTADOS E DISCUSSÕES}

Para a discussão dos dados, elencamos quatro temas centrais para apresentar e analisar os aspectos relevantes encontrados: 


\subsection{A RESPONSABILIDADE AO TORNAR-SE PAI}

O momento em que os entrevistados participaram da entrevista era o do nascimento do seu primeiro, segundo ou terceiro filho, período de transformações ocorrendo com eles próprios e com suas famílias. Um período de transição e de constituição de novos papéis, especialmente para pais de primeiro filho.

Ocorre que a mudança de papéis dos membros da família é processo que leva a uma reestruturação e readaptação, em que seus componentes passam a redimensionar valores, expectativas e prioridades (BORNHOLDT; WAGNER; STAUDT, 2007). Esta situação pode ser observada no seguinte relato:

Eu sempre ouvi dizer muito que quando você é pai e mãe, muda muito a concepção, o pensamento. Primeiro lugar, você já deixa de pensar em você mesmo. Quando você é solteiro, você [pensa]: 'ah, quero tal coisa, você vai e faz'. Você tendo filho já não, você vai sair, já pensa nele, deixa você em segundo plano. (GUSTAVO).

A individualidade e a liberdade se modificam com a chegada do filho. Para muitos pais, a paternidade se define pela redução da liberdade, levando-os a re-significá-la e a dominar suas vontades (FREITAS et al., 2009).

Arilha (1998) afirma que a constituição de uma família para o homem se liga incontestavelmente à ideia de responsabilidade, de vir a ser responsável pelo outro. É justamente neste sentido que Gustavo em uma de suas falas menciona que ter um filho "[...] aumenta a responsabilidade, amadurece".

Este pai ainda diz que "[...] a gente é moleque, a gente quer sair, jogar bola, mas agora a gente tem uma responsabilidade muito grande”, isto é, o desvelar da paternidade é passagem significativa para o homem e etapa necessária para a aquisição do código masculino de sociabilidade, pois quando deixa para trás o tempo de zoeira, é quando se torna adulto efetivamente (SARTI, 2011).

Assim, ser pai exige seriedade, tempo, planejamento financeiro e o abandono de uma vida mais descomprometida. É diante do nascimento do filho que assume, de fato, a responsabilidade com a família.

Destaca-se que esta responsabilidade pela família pode ser associada a uma das características da família patriarcal, na qual cabe ao bom pai prover o sustento financeiro da família (OLIVEIRA; BRITO, 2009). Nessa lógica, caso não consiga prover, põe em xeque, inclusive, a sua masculinidade (FREITAS et al., 2009), como apontado no próximo tópico.

\subsection{O IDEAL DE HOMEM PROVEDOR}

Foi observado que para os participantes, ser o provedor financeiro da família é um objetivo de vida, como as falas a seguir expressam:

[...] minha esposa, que quero dar uma estabilidade, de repente, conseguir um emprego que eu tenha estabilidade e eu consiga talvez deixar ela só cuidando do filho. Então eu penso que se eu conseguisse manter tudo sozinho... Mas é que nos dias de hoje não dá, é quase impossível. (PAULO). 
Eu não quero que ela volte [a trabalhar], pra cuidar mais dele [bebê], porque depois chegando a um aninho, aí volta, porque tem o meu salário e o dela, aí depois não vai ter mais. (GUSTAVO).

Fonseca (2004) explica que o papel do pai-provedor ainda é um ideal de muitos homens da classe trabalhadora, mesmo que dificilmente consigam atingir. Sarti (2011) por sua vez também aponta ser este o padrão ideal para camadas populares: o papel masculino é de prover teto e alimento e é visto como um atributo moral, do qual eles se orgulham.

Porém, o que encontramos na atualidade é que as mulheres também trabalham fora do lar. Ocorre que nesses casos, quando ambos os cônjuges trabalham, a mulher passa a sofrer com a dupla jornada: do trabalho e da casa com os filhos (WANG; JABLONSKI; MAGALHÃES, 2006).

Neste sentido, para manter a harmonia na casa, o papel feminino é de adequar seus horários de trabalho com o cuidado e demandas dos filhos e, se necessário, desistem do emprego, em favor das necessidades destes, sustentando o modelo de família em que o homem, indubitavelmente, é encarregado da provisão financeira (NEGREIROS; FÉRES-CANEIRO, 2004).

Portanto, os depoimentos apontaram para papéis mais tradicionais e rígidos, em que homens aspiram prover sozinhos suas famílias e mulheres devem ocupar o papel de mãe.

\subsection{A DIVISÃO DAS TAREFAS DOMÉSTICAS E O CUIDADO COM OS FILHOS}

Sobre a divisão das tarefas domésticas na casa, um dos participantes assim descreveu a rotina familiar:

Ah, ajudo a dar banho nos meninos pra arrumar para a creche, eu ajudo ela [...] Nós dividimos as coisas, só limpar a casa que não, pelo amor de Deus! Eu chego cansado do dia inteiro, mas assim, agora, principalmente porque tem a pequena [bebê], o que tiver que fazer eu faço, menos limpar a casa! (ANTÔNIO).

Apesar do discurso de que divide as tarefas, observa-se que algumas atividades específicas Antonio relata não fazer, o que nos leva a entender que a companheira, de fato, é a principal responsável pelas tarefas domésticas.

Bruschini e Ricoldi (2012, p. 263) em seus estudos sobre a participação masculina no trabalho doméstico, constataram a mesma referência à ‘ajuda' em suas entrevistas: "quando há mulheres na família disponíveis para executá-lo, consubstancia-se nesse auxílio periférico e não obrigatório".

0 mesmo sentido aparece em outros relatos, em que a responsabilização das tarefas de casa é da mulher, que parece não ter escolha, contando, quando possível, com o auxílio do homem:

Sempre ela faz mais. Ela chega, faz o jantar, os dois passam o dia fora. Aí eu pego a menina [filha mais velha] na creche, ela já vai cuidando do jantar, lava a louça, essas coisas... Mas fica mais pra ela. (MATHEUS).

Essas coisas [tarefas doméstica] eu não faço sempre, acho que teria que ajudar mais vezes, perto do que ela faz, porque eu ajudo ela pouco. (ROBERTO). 
Embora os participantes dissessem se envolver nas atividades domésticas, o teor das falas leva a inferir que as mulheres precisam assumir determinadas tarefas, diante das negatórias de seus companheiros.

Jablonski (2010) entende que a construção simbólica de gênero, que determina o que é masculino e feminino, reflete no interior das famílias, nas atividades do cotidiano. Para o autor, o processo de socialização de meninos, em que dificilmente são incumbidos de atividades domésticas, contribui para que este tipo de dinâmica seja carregado para o novo núcleo familiar.

Quanto à participação do pai nos processos de cuidado dos filhos, identificou-se também o caráter de ajuda:

Eu participo de tudo, ajudo em casa, faço de tudo, ajudo arrumar a casa, ajudo também a levar ao médico. A gente sempre deixa a desejar um pouco [...] porque às vezes eu ajudo, mas às vezes eu saio de casa num final de semana, saio com algum colega, aí deixo ela só, cuidando da casa e das crianças, acho que é nesse ponto aí. (MATHEUS)

Dados semelhantes foram encontrados por Jablonski (2010), nos quais a participação masculina apesar de ser maior atualmente, persiste como subsidiária, predominantemente complementar. Sua pesquisa apontou ainda que as mulheres são as que dão conta das tarefas do lar, faltam no trabalho, caso necessário, para tratar de assuntos relacionados aos filhos e há pouca contribuição do homem nesse quesito, o que leva a maior sobrecarga das mulheres nas tarefas familiares.

Reconhece-se que os pais se sentem perdidos diante de atividades que revelam ter medo de executar, contudo, assim justificam essa posição:

É que a gente, pai, sempre tem medo, né? Porque a mãe sempre tem mais cuidado que o pai. Tem pai que a gente vê que gosta de fazer, mas eu tenho medo. Sei lá, parece que eu tenho medo de dar o remédio, tem um jeitinho de dar [...] eu tenho medo, eu tenho aquele receio. Homem é meio que bruto, mulher é mais cuidadosa, é sempre a mais cuidadosa, tem mais jeitinho. (PEDRO).

Entende-se que é comum encontrar obstáculos após o nascimento do filho, o que pode ser o caso deste pai, já que o medo pode estar associado à falta de conhecimento e informação (OLIVEIRA; BRITO, 2009). No entanto, esta situação chama a atenção e leva a argumentação de Schwengber e Silveira (2012, p. 98):

A noção da "ajuda" paterna [...] parece sustentar-se na ideia de que a mulher é biologicamente preparada para a maternidade, como se sua capacidade de ser mãe estivesse sempre adormecida e florescesse durante a gestação. Parece-nos que é esse discurso que coloca o homem no lugar do 'não-preparado' ou do 'menos preparado' para a experiência de 'criar' filhos/as.

A expectativa de que a mulher é preparada para a maternidade, corrobora com os estudos de Bornholdt, Wagner e Staudt (2007), quando pais também se justificam sobre pouco participarem no

Interfaces Científicas • Aracaju • V.9 • N.2 • p. 154 - 165 • 2021 - Fluxo Contínuo 
cuidado dos filhos, mencionando maior facilidade das mulheres no cuidado, como se estas tivessem uma espécie de habilidade natural feminina.

Apesar de os participantes da pesquisa descreverem-se como mais engajados, com atitudes mais igualitárias em relação à vida familiar, tarefas domésticas e cuidado com os filhos, a maior responsabilidade pareceu ficar com as mulheres, pois no entendimento deles, a mulher é a expressão do cuidado e preparada para a maternidade.

\subsection{REPENSANDO A PATERNIDADE - O PAI AMIGO}

O modelo de paternidade mais envolvida, afetiva e solidária, pode ser vista como um novo movimento dialético, fazendo com que os homens passem a refletir sobre suas próprias concepções sobre ser pai, levando a (des) construir a paternidade incorporada a partir das relações sociais desde menino, sobretudo com o próprio pai (FREITAS; COELHO; SILVA, 2007).

Neste sentido encontramos relatos em que as experiências com o próprio pai levam a repensar a relação dos participantes com seus filhos:

Às vezes o filho dá um pouco de trabalho, porque quer brincar, aí eu dou um pouco de atenção, porque eu penso nisso, eu não tive pai, meu pai morreu quando eu tinha nove anos, então eu procuro fazer o que eu não tive. Eu procuro dar [atenção] para o meu filho, na questão de ser pai mesmo, de estar junto, de brincar, porque eu não tive. [...] Ah, eu ajudo bastante, brinco bastante com ele, levo pra passear, quando a mãe não pode ir eu levo, também converso com ele, [pergunto] como foi a escola... (ROBERTO).

Ah, eu procuro ser muito presente, né? Hoje eu tento tomar muito como exemplo a convivência com meu pai. Eu tinha medo do meu pai. Naquela época os pais eram rígidos. Sempre tive muito medo do meu pai. Então, hoje, é que nem minha esposa fala, eu tento passar para meus filhos algo totalmente diferente. (MÁRCIO).

Nesta perspectiva, observa-se que os pais têm se preocupado em paternar os filhos, acompanhando o desenvolvimento de forma mais próxima, permeada por afetos e negociações, cedendo espaço para atitudes de cuidado e envolvimento (FREITAS et al., 2010; OLIVEIRA; BRITO, 2009). Entretanto, revelam manter ainda posturas mais firmes perante algumas situações que julgam necessárias:

Eu sou rigoroso, quando eu mando fazer, tem que fazer, se não fizer, eu pego no pé e ponho de castigo. Eles ficam com raiva, é autoridade... A mãe, ela é um pouco mais solta, ela tem um pouquinho mais de dó, e eu já não, eu não sei se foi o modo que eu fui criado, né... Ou faz ou apanha. Apanhei bastante. Fui bem educado, não posso reclamar da minha mãe. (MIGUEL)

Desse modo, os relatos se assemelham ao que as pesquisas têm levantado, quando indicam que a paternidade está em transformação: transita entre valores novos, como o pai que se envolve na 
educação e acolhe os filhos, e valores tradicionais, como o pai autoritário (GOMES; RESENDE, 2004; WANG; JABLONSKI; MAGALHÃES, 2006).

Apesar de a sociedade levantar a bandeira do 'novo pai', Schwengber e Silveira (2012) argumentam que da forma como tem se colocado, reafirma-se a ideia de obrigação da mulher de cuidado com a prole, apontando que a paternidade mais envolvida seria uma novidade ou uma sorte para a mulher ter com quem dividir a responsabilidade. Porém, o que se espera não é apenas mais um bom marido (protetor, provedor, independente etc.), mas alguém que divida, em condições de igualdade, as cargas da vida doméstica (WANG; JABLONSKI; MAGALHÃES, 2006).

Em vista disso, o homem tem sido levado a refletir para além dos estereótipos, revendo suas obrigações, passando a repensar sua própria identidade e sobre o que é ser pai (GOMES; RESENDE, 2004; WANG; JABLONSKI; MAGALHÃES, 2006).

Há de se reconhecer que a participação que os pais se referiam ao longo das entrevistas centrou-se no envolvimento afetivo com os filhos, no estabelecimento da amizade e na construção de espaço para o diálogo, indicando um distanciamento das formas assumidas em outras épocas pelos pais em relação a seus filhos.

\section{CONSIDERAÇÕES FINAIS}

Conforme identificado no estudo, verificou-se que a posição de pai-provedor permanece no ideário dos entrevistados. Tornar-se pai significa, de fato, ser adulto, e está diretamente atrelada à ideia de responsabilidade, de modo que prover a família apareceu como um dever, em que desejam manter a sua provisão, mesmo quando não conseguem fazê-lo sozinhos, reforçando o histórico papel masculino na família.

Embora os pais relatem dividir as tarefas domésticas e os cuidados com os filhos de forma mais equânime, parece que estas responsabilidades ainda assim são funções da mulher, quando obrigatoriamente faz atividades negadas pelos homens. Assim, considera-se que as definições de gênero ainda marcam o modo de vida das famílias deste estudo, contudo, mudanças estão em curso, especialmente por meio da preocupação de paternar os filhos, buscando acompanhar o desenvolvimento destes.

Recomenda-se que a discussão sobre gênero, suas transformações e seus reflexos na esfera da família sejam mais investigadas, uma vez que não se esgotaria este assunto neste estudo. Mudanças acerca das consideradas masculinidades se colocam como emergentes/urgentes para análise, uma vez que repercutem diretamente no papel do homem dentro do núcleo familiar.

\section{REFERÊNCIAS}

ARILHA, M. Homens: entre a 'zoeira e a "responsabilidade”. In: ARILHA, M; RIDENTI, S. G. U; MEDRADO, B. (org.) Homens e masculinidades: outras palavras. São Paulo: ECOS/Editora 34, 1998. p. 51-77.

BARDIN, L. Análise de conteúdo. São Paulo: Edições 70, 2010. 
BORNHOLDT, E. A.; WAGNER, A.; STAUDT, A. C. P. A vivência da gravidez do primeiro filho à luz da perspectiva paterna. Psicologia Clínica, Rio de Janeiro, v. 19, n. 1, p. 75-92, 2007. Disponível em: http://www.scielo.br/pdf/pc/v19n1/06.pdf. Acesso 20 jul. 2016.

BRUSCHINI, M. C. A.; RICOLDI, A. M. Revendo estereótipos: o papel dos homens no trabalho doméstico. Revista Estudos Feministas, Florianópolis, v. 20, n. 1, janeiro-abril, p. 259-287, 2012. Disponível em: http://www.scielo.br/pdf/ref/v20n1/a14v20n1.pdf. Acesso em: 10 jul. 2016.

DEL PRIORE, M. Pais de ontem: transformações da paternidade no século XIX. In: DEL PRIORE, M; AMANTINO, M. (org.) História dos homens no Brasil. São Paulo: Editora Unesp, 2013. p. 185-244.

DESLANDES, S. F. O projeto de pesquisa como exercício científico e artesanato intelectual. In: DESLANDES, S. F.; GOMES, R.; MINAYIO, M. C. S. (org). Pesquisa social: teoria, método e criatividade. 28. ed. Petrópolis: Vozes, 2009. p. 31-60.

FONSECA, C. A certeza que pariu a dúvida: paternidade e DNA. Revista Estudos Feministas, Florianópolis, v. 12, n. 2, p. 13-34, maio/ago. 2004. Disponível em: http://www.scielo.br/pdf/ref/ v12n2/23958.pdf. Acesso em: 10 jul. 2016.

FREITAS, W. M. F. et al. Paternidade: responsabilidade social do homem no papel de provedor. Revista Saúde Pública, v. 43, n. 1, p. 85-90, 2009. Disponível em: http://www.scielo.br/pdf/rsp/ v43n1/6868.pdf. Acesso em: 18 jul. 2016.

FREITAS, W. M. F.; COELHO, E. A. C.; SILVA, A. T. M. C. Sentir-se pai: a vivência masculina sob o olhar de gênero. Cadernos de Saúde Pública, v. 23, n. 1, p. 137-145, 2007. Disponível em: http://www. scielo.br/scielo.php?script=sci_arttext\&pid=S0102-311X2007000100015. Acesso em: 20 jul. 2016.

GOMES, A. J. S.; RESENDE, V. R. O pai presente: o desvelar da paternidade em uma família contemporânea. Psicologia: Teoria e Pesquisa, v. 20, n. 2, p. 119-125, 2004. Disponível em: http:// www.scielo.br/pdf/ptp/v20n2/a04v20n2.pdf. Acesso em: 1 jul. 2016.

GOMES, R. Sexualidade masculina, gênero e saúde. Rio de Janeiro: Editora FIOCRUZ, 2008.

JABLONSKI, B. A divisão de tarefas domésticas entre homens e mulheres no cotidiano do casamento. Psicologia Ciência e Profissão, v. 30, n. 2, p. 262-75, 2010. Disponível em: http://www. scielo.br/pdf/pcp/v30n2/v30n2a04.pdf. Acesso em: 4 maio 2017.

MINAYO, M. C. S. O desafio da pesquisa social. In: DESLANDES, S. F.; GOMES, R.; MINAYO, M. C. S. (orgs). Pesquisa social: teoria, método e criatividade. 28. ed. Petrópolis: Vozes, 2009. p. 9-30. 
NEDER, G. Ajustando o foco das lentes: um novo olhar sobre a organização das famílias no Brasil. In: KALOUSTIAN, S. M. (org.) Família brasileira, a base de tudo. São Paulo: Cortez; Brasília, DF: UNICEF, 1994. p. 26-46.

NEGREIROS, T. C. G.; FÉRES-CARNEIRO, T. Masculino e feminino na família contemporânea. Estudos e Pesquisas em Psicologia, Rio de Janeiro, v. 4, n. 1, jun, p. 34-47, 2004. Disponível em: http:// pepsic.bvsalud.org/pdf/epp/v4n1/v4n1a04.pdf. Acesso em: 12 jul. 2016.

OLIVEIRA, E. M. F., BRITO, R. S. Ações de cuidado desempenhadas pelo pai no puerpério. Escola Anna Nery, v. 13, n. 3, p. 595-601, 2009. Disponível em: http://www.scielo.br/pdf/ean/v13n3/ v13n3a20.pdf. Acesso em: 13 jul. 2016.

SARTI, C. A. A família como universo moral. In: SARTI, C. A. (org.) A família como espelho: um estudo sobre a moral dos pobres. 7. ed. São Paulo: Editora, 2011. p. 55-86.

SARTI, C. A. Famílias enredadas. In: ACOSTA, A. R; VITALE, M. A. F. (org.) Família: redes, laços e políticas públicas. 5. ed. São Paulo: Cortez. Coordenadoria de Estudos e Desenvolvimento de Projetos Especiais - PUC/SP, 2010. p. 21-36.

SCHWENGBER, M. S. V; SILVEIRA, C. C. Paternidade em deslocamento: o caso do pai amigo e presente. Revista Entreideias: educação, cultura e sociedade, n. 19, jan, p. 91-101, 2012. Disponível em: http:// www.portalseer.ufba.br/index.php/entreideias/article/view/5257/4302. Acesso em: 12 jul. 2016.

WANG, M. L.; JABLONSKI, B.; MAGALHÃES, A. S. Identidades masculinas: limites e possibilidades. Psicologia em Revista, p. 54-65, 2006. Disponível em: http://periodicos.pucminas.br/index.php/ psicologiaemrevista/article/view/243. Acesso em: 15 jul. 2016. 
1 Doutoranda no Programa de Pós-Graduação em Saúde, Interdisciplinaridade e Reabilitação, da Faculdade de Ciências Médicas, da Universidade Estadual de Campinas - UNICAMP; Assistente Social. E-mail: n_benegas@yahoo.com.br.

2 Doutora em Saúde Mental pela Faculdade de Ciências Médicas; Assistente Social; Professora Colaboradora do Departamento de Desenvolvimento Humano e Reabilitação, da Faculdade de Ciências Médicas, da Universidade Estadual de Campinas - UNICAMP. Reside em CampinasSP. E-mail: mfcf@unicamp.br

\section{(c) (1) (2)}

Este artigo é licenciado na modalidade acesso abertosob a Atribuição-Compartilhalgual CC BY-SA

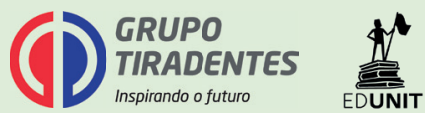

